\title{
Partner notification and partner treatment for chlamydia: attitude and practice of general practitioners in the Netherlands; a landscape analysis
}

Ingrid V. F. van den Broek ${ }^{1 *}$ (D, Gé A. Donker ${ }^{2}$, Karin Hek ${ }^{3}$, Jan E. A. M. van Bergen ${ }^{4,5}$, Birgit H. B. van Benthem ${ }^{4}$ and Hannelore M. Götz ${ }^{4,6,7}$

\begin{abstract}
Background: Chlamydia prevalence remains high despite scaling-up control efforts. Transmission is not effectively interrupted without partner notification (PN) and (timely) partner treatment (PT). In the Netherlands, the follow-up of partners is not standardized and may depend on GPs' time and priorities. We investigated current practice and attitude of GPs towards PN and PT to determine the potential for Patient-Initiated Partner Treatment, which is legally not supported yet.
\end{abstract}

Methods: Multiple data-sources were combined for a landscape analysis. Quantitative data on (potential) PT were obtained from prescriptions in the national pharmacy register (2004-2014) and electronic patient data from NIVELPrimary Care Database (PCD) and from STI consultations in a subgroup of sentinel practices therein. Furthermore, we collected information on current practice via two short questionnaires at a national GP conference and obtained insight into GPs' attitudes towards PN/PT in a vignette study among GPs partaking in NIVEL-PCD.

Results: Prescription data showed Azithromycin double dosages in 1-2\% of cases in the pharmacy register (37.000 per year); probable chlamydia-specific repeated prescriptions or double dosages of other antibiotics in NIVEL-PCD (115/1078) could not be interpreted as PT for chlamydia with certainty. STI consultation data revealed direct PT in $6 / 100$ cases, via partner prescription or double doses. In the questionnaires the large majority of GPs (>95\% of 1411) reported to discuss PN of current and ex-partner(s) with chlamydia patients. Direct PT was indicated as most common method by $4 \%$ of 271 GPs overall and by $12 \%$ for partners registered in the same practice. Usually, GPs leave further steps to the patients (83\%), advising patients to tell partners to get tested (56\%) or treated (28\%). In the vignette study, 16-20\% of 268 GPs indicated willingness to provide direct PT, depending on patient/partner profile, more (24-45\%) if patients would have the chance to notify their partner first.

Conclusion: GPs in the Netherlands already treat some partners of chlamydia cases directly, especially partners registered in the same practice. Follow-up of partner notification and treatment in general practice needs more attention. GPs may be open to implement PIPT more often, provided there are clear guidelines to arrange this legally and practically.

Keywords: Partner notification, Partner treatment, Expedited partner therapy, Patient-initiated partner treatment, General practice, Sexually transmitted infections, Chlamydia trachomatis

\footnotetext{
* Correspondence: Ingrid.van.den.Broek@rivm.nl

${ }^{1}$ Epidemiology and Surveillance Unit, Centre for Infectious Diseases Control,

RIVM, Bilthoven, The Netherlands

Full list of author information is available at the end of the article
} 


\section{Background}

Chlamydia trachomatis (hereafter "chlamydia") incidence remains high in the Netherlands despite targeted control efforts. The estimated report rate was 310/100,000 in 2015 and 272/100.000 in 2010. [1] STI centres provide low-threshold additional care prioritising high-risk groups. Young people under 25 years of age and other high-risk groups can be tested for chlamydia without cost at STI clinics. The general practitioner (GP) still performs the largest number of STI consultations (estimated at two thirds or more) [1]; a minority uses private (self-)care and some get tested in the hospital (gynaecologist) after referral. The number of chlamydia tests has increased over the years but diagnostic rates have not gone down: an estimated 54,000 infections were detected at GPs and STI clinics in 2015: 35,000 at the GP and 19,000 in STI clinics. [1] New routes of chlamydia control need to be explored and integrated in the STI care system.

Effective partner notification (PN) and partner treatment (PT) are essential to prevent re-infection and further spread. Re-infections for chlamydia are common, occurring in 14-20\% of cases [2-5].The importance of PN for chlamydia has been demonstrated in several studies [6] and is addressed in all Dutch STI care manuals and guidelines [7, 8]. Persons notified by a sexual partner are at high risk of infection; in Dutch STI clinics the infection rate was $36 \%$ among women and $32 \%$ among heterosexual men who visited due to notification for chlamydia. [1]

Dutch guidelines advise PN for chlamydia patients (a) in case of symptomatic infections for partners in the period 6 weeks prior to the onset of symptoms and (b) in case of asymptomatic infections for all partners in the last 6 months. According to GP guidelines, [7, 8] PN should be discussed in order to motivate chlamydiapatients to inform their sex partners, or alternatively, GPs should offer to help with notification or refer to other services. The advice is to tell the partner to see a health professional to get tested or to get treated directly. GPs can offer presumptive treatment for a partner presenting for consultation. Online tools for patients and GPs are available: 'www. Thuisarts.nl' gives instructions on how to perform PN and 'partnerwaarschuwing.nl' [9] can be used to arrange individual PN after diagnosis, but uptake at GPs is still limited [10].

A way to improve partner management is to provide practical tools to simplify procedures for both patients and GPs. A systematic review showed that providing direct treatment for the current sexual partner, so-called Expedited Partner Therapy (EPT), can be an effective strategy. [6] Patients give a prescription or medication to their sexual partners to treat the infection or, alternatively, partners obtain medication from the pharmacy directly. [11] EPT is efficacious in reducing repeated infections in index patients and increasing the number of partners treated. [12-15] The implementation of EPT reduced the chlamydia test positivity in a large scale pilot in Washington State, USA, although this may not have been an exclusive effect of the intervention. [16] The method is used widely in the USA: EPT is permissible in 38 states and potentially allowable in 8 states. [17] Also in the UK, EPT or similarly, Accelerated partner therapy (APT), is seen as a viable option. [18-20]

In the Netherlands, direct PT via the partner, referred to as Patient Initiated Partner Therapy (PIPT), is not officially implemented, because a physician is legally required to have contact with a patient before prescribing medication, to explain the reason for medication and to check medical history and allergies. In 2016, the Project Investigating options for Patient Initiated Contact treatment for Chlamydia in the Netherlands (PICC-UP) started, with the objective to investigate the potential of PIPT as an effective method for improving PT. The project covers other issues of PIPT, including the legal steps needed for implementation. Here we describe an initial landscape analysis on the current level of practice of PN/PT and (potential) direct PT for chlamydia in the general practice, as well as the attitude and opinions of Dutch GPs towards implementation of direct PT, provided it would be possible in future. [21]

\section{Methods}

This study was set up to combine multiple sources to explore PN/PT practices among GPs in the Netherlands, both prescription data (paragraph 1) and questionnaire data (paragraph 2) were used.

\section{Quantitative data on current practice Chlamydia-specific double dosage prescriptions as (potential) indicator for PIPT}

\subsection{The SFK database ('Stichting Farmaceutische} Kengetallen' $^{1}$ ) contains anonymous data on prescriptions covering 95\% of public pharmacies (i.e. extramural pharmacies) in the Netherlands. Information is available on the date of issue, delivered amount of tablets, average daily dose recommended to be taken, delivered Defined Daily Dose (DDD); the indication for the prescribed medication is not registered in the SFK. We selected (2004-2015) Azithromycin prescriptions typical and thought to be exclusively used for chlamydia (single dose of $1 \mathrm{~g}$ Azithromycin for 1 day or multiple dose thereof), and calculated the proportion of double/ multiple dosage prescriptions that could reflect simultaneous PT for chlamydia. This method had been validated before in a previous (unpublished) 
report, showing that prescriptions of Azithromycin single dose as specific treatment for chlamydia compare well to estimates of the number of chlamydia infections reported nationally.

1.2 The NIVEL-PCD was used to study episode-based data from the electronic patient registration (2015). This network includes over 400 practices, nationally representative by age and gender and by population density and geographical practice distribution. ${ }^{2}$ The database system records data on morbidity, prescriptions and referrals. Analyses were performed with the aim to tabulate single versus double dosages with a diagnosis code for chlamydia infection, as well as repeated prescriptions within a period of 2 weeks after the initial prescription, seen as (potential) cases of PIPT. Chlamydia episodes were identified by ICPC codes (vaginitis (X84), cervicitis (X85) and Pelvic Inflammatory Disease (PID) (X74) in women, and orchitis/epididymitis (Y74) and other genital diseases (Y99) in men) combined with specific chlamydia-prescriptions, based on an earlier developed definition of chlamydia in the absence of a specific ICPC code for chlamydia. [22] Prescription data are ATC-coded. Standard first choice treatment for genital chlamydia is Azithromycin (1 g single dose; ATC-code J01FA10); we also looked at dosages of Doxycycline (2 dd 100 mg 7 days; J01AA02), given for anal infections or epididymitis/orchitis and Amoxicillin (during pregnancies, 3dd 500 mg 7 days; J01CA04). We studied the dosage prescribed, based on frequency (times per day), unit, total number of units prescribed and whether it was a repeat prescription. Episodes with one of the ICPC codes and one of the ATC codes were selected. Episodes with no prescription of antibiotics were assumed not to be chlamydia; those with missing information on dosage were excluded from the analyses.

\section{Consultations}

1.3 Sentinel practices $(N=42)$ of NIVEL Primary Care Database (NIVEL-PCD), collect data specific for STI-consultations. GPs are requested to routinely complete a questionnaire for each registered new disease episode in a patients' electronic record with an ICPC-code (International Classification of Primary Care (ICPC-1)) concerning STI/HIV issues. This contains, with anonymous identification numbers, information on testing and diagnosis, patient demographics, reason for consultation and sexual risk behaviour. Since January 2015, questions concerning PN and PT were added; we used 2015 data for the current analyses.

\section{Questionnaire data on current practice of PN/PT and attitude towards PIPT}

1.4 For a large pre-conference survey, GPs were asked to fill in an online questionnaire at the time of registration for a national GP conference (November 2015). This survey included a question on partner notification of current and ex-partners for patients diagnosed with STIs.

1.5 At the same national GP conference, a short questionnaire was handed out on site to GP participants. This contained questions on the most common methods for PN and PT in the general practice.

1.6 In the NIVEL-PCD, a vignette study on practice and attitude of GPs towards partner management was performed. An annual online questionnaire is distributed among GPs in this network. We included in this questionnaire (in 2016) two case descriptions or 'vignettes', known as a useful way to measure reported and/or intended physician practices in an outpatient setting. [23, 24] The vignettes described two hypothetical chlamydia positive patients: (i) a 'low risk' case, woman with a steady relationship (25 years, Dutch; partner patient in the same practice), chlamydia probably acquired through an incidental casual partner and (ii) a presumed 'higher risk' case: young man (17 years, migrant background), who had 4 different female partners in the last 4 months, and was still seeing one of these. We asked for the GPs intention for PN and PT and his/ her attitude towards PIPT.

\section{Results}

\section{Prescription data}

1.1 In total, 443,512 chlamydia-specific prescriptions of Azithromycin (1 g 1d) were registered in the SFK between 2004 and 2015 (increasing, average 37,000 per year). Of these, $99.3 \%$ had a single dosage prescription and $0.7 \%$ a double or (incidental) triple or more, which may have been direct partner treatment. A clear increase in double dose prescriptions was observed from 2013 onwards: it rose from below $0.5 \%$ to $1.5 \%$ in the period 2013-2015, much more obvious in men than in women (see Fig. 1).

1.2 For the pilot study on potential PT in the NIVEL PCD, data from 311 general practices in 2015 was available. We identified 18,599 episodes with one of the five relevant ICPC codes; for a large part of these no antibiotic was prescribed which were therefore assumed not to be chlamydia infections 


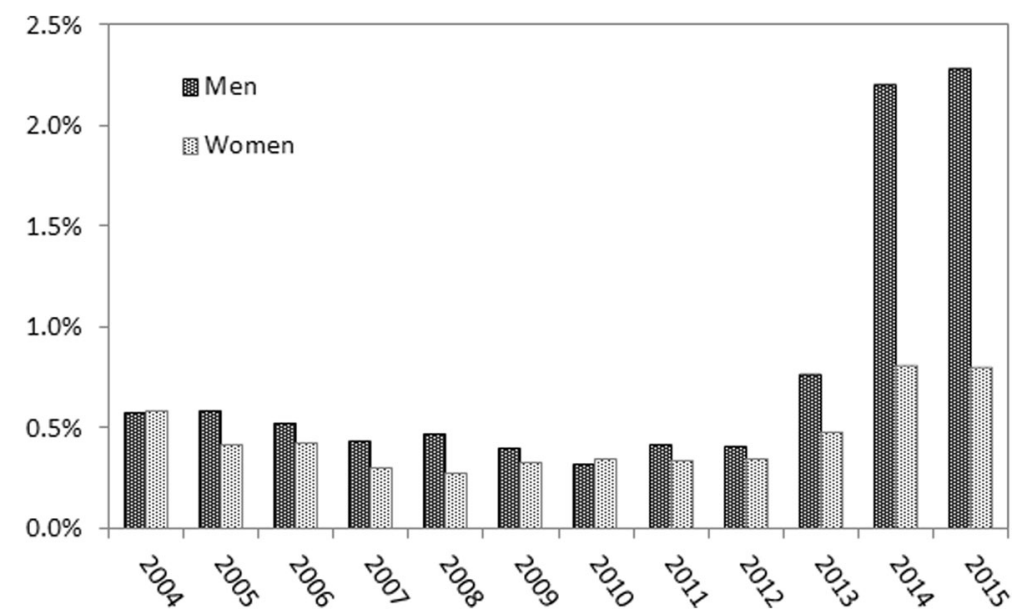

Fig. 1 Proportion of double dosages of Azithromycin (1 g single dose) prescribed in public pharmacies in The Netherlands 2004-2015, in men and women

and excluded. For 902 chlamydia episodes (in 891 patients), a total of 1078 chlamydia-related antibiotic prescriptions were recorded with dosage information. The major part of the prescriptions was Azithromycin, a smaller part Doxycycline and a few Amoxicillin (with specified dosages or a multiple dose thereof, see Table 1). Double dosages were prescribed in $2.1 \%$ of Azithromycin-treated chlamydia episodes: in $2.8 \%$ of women and $1.3 \%$ of men (12/427 women and 5/372 men; difference not significant; 3 cases gender unknown), most commonly in the age group 30-39 years $(3.1 \% ; 6 / 191)$ versus $2.1 \%$ in $<20$ years $(2 / 97)$ and $2.1 \%$ in $20-29$ years old $(9 / 420)$.

Furthermore, double dosages were found for $31.1 \%$ of Doxycycline episodes and in none of the Amoxicillin-treated ones. The double-dosed Doxycycline were prescriptions of 28 dosages instead of 14 dosages, unlikely to be PT, probably prescriptions for 2 weeks instead of 1 week, as indicated for epididymitis caused by chlamydia (but duration was not consistently reported). Double-dosages were indeed more common among men than among women (46.2\% of men treated with doxycycline and $11.1 \%$ of women). The proportion of chlamydia episodes with repeated prescriptions was $12.6 \%$, of which $7.6 \%$ was registered on the same day (66/902). Of the total, $11.9 \%$ was treated with the same antibiotic and $0.8 \%$ with a different antibiotic. These proportions did not relate to age group or gender.

1.3 In the 42 sentinel practices, 100 chlamydia cases were recorded in 470 STI-consultations (reported in 2015). The most common way for GPs to inform the patient of his/her chlamydia infection was by phone $(n=65)$ or personal consultation $(n=29)$. The remaining cases heard it from another care provider (under whose responsibility they were tested; $n=5$ ) or no follow-up was done $(n=1)$, as the GP stated 'the patient had already been treated blind, so no follow-up visit was needed'. PN was discussed with the 94 cases contacted: most GPs $(n=85)$ left it to the patient to take further steps; for two cases PN was done by the GP or assistant, while two cases were referred to PN services (five no answer). For 72 of the 94 cases (77\%) GPs indicated they did not treat the partner, while 12 said they advised to tell the partner to come to the practice (13\%), either for a test $(n=6)$ or for direct treatment $(n=5)$ or both

Table 1 Type of antibiotics used for chlamydia: per prescription and per episode, in 2015

\begin{tabular}{|c|c|c|c|c|c|c|c|c|}
\hline \multirow{2}{*}{$\begin{array}{l}\text { Antibiotics } \\
\text { Azithromycin (1 g 1d) }\end{array}$} & \multicolumn{2}{|c|}{$\begin{array}{l}\text { Chlamydia } \\
\text { prescriptions } \\
\text { N\% }\end{array}$} & \multicolumn{2}{|c|}{$\begin{array}{l}\text { Chlamydia } \\
\text { episodes } \\
\text { N \% }\end{array}$} & \multicolumn{2}{|c|}{$\begin{array}{l}\text { Episodes with double dose } \mathrm{N} \\
\%\end{array}$} & \multicolumn{2}{|c|}{$\begin{array}{l}\text { Episodes with repeated Ct- } \\
\text { prescriptions }^{a}\end{array}$} \\
\hline & 937 & 86.9 & 802 & 88.9 & 17 & 2.1 & 93 & 11.6 \\
\hline Doxycycline (2dd 100 mg 7d) & 123 & 11.4 & 106 & 11.8 & 33 & 31.1 & 20 & 18.9 \\
\hline Amoxicillin (3dd 500 mg 7d) & 18 & 1.7 & 15 & 1.7 & 0 & 0 & 2 & 13.3 \\
\hline Total & 1078 & & 902 & & 50 & & 115 & \\
\hline
\end{tabular}

a episodes had multiple prescriptions of the same or different antibiotics (maximum 4 recorded) 
$(n=1)$; four gave no answer. PIPT was applied in six cases (6.4\%): the GPs wrote a direct, extra medical prescription for partners of four cases, while they prescribed a double dosage for two cases to treat partners simultaneously (Fig. 2). No clear correlations were found between patient characteristics (gender, sexual preference, age, reason for consultation) and PN/PT.

\section{Current practice of PN/PT and attitude towards PIPT}

1.4 The online pre-conference survey was filled-in by 1411 GPs (53\% of a total of 2650 conference participating GPs). The majority of GPs discusses PN of the current partner and the ex-partner with the patient. Of all GPs, 80\% indicated to discuss PN always and 18\% mostly with their STI-patients (Fig. 3). The GPs discussed PN significantly less frequently for ex-partners than for current partners (Chi-square $p<0.001$ ).

1.5 The short hand-out questionnaire was completed by 271 participants at the GP conference. The most common method of PN reported was to discuss this and leave it to the patient to take further steps (83\%). In most cases, the GP would advise the patient to tell his/her partner to get tested (56\%) or get treated (28\%). Direct PT was used for some cases: $4 \%$ of GPs treat partners directly: $2 \%$ through prescription for the partner and $2 \%$ through a double dosage to the index. When the partner is also a patient in the same practice, $12 \%$ of GPs write a prescription for him/her at the same time as the index (Fig. 4).

1.6 The vignette study in the annual questionnaire to NIVEL PCD was answered by 289 of 438 persons (response 66\%), of which we included the GPs ( $n=$ 268) for our analysis (21 questionnaires were filled in by GP assistants or managers). The large majority of GPs (87\%) indicated they would discuss PN with the patient and leave it to the patient to notify the partner(s) (Table 2). PN via the MHS or another (online) service was more commonly suggested for the high risk than for the low risk case (74\% vs $37 \%)$. PT advice was via the patient, to inform the partner to consult a doctor to either get tested (76\%) or to get direct treatment (55\%). PIPT was an option for about one in five GPs: $16 \%$ would write a prescription for the partner, while $6 \%$ would write a double dosage prescription for the patient to treat the partner simultaneously. In the hypothetical situation that a patient could notify the partner first, prescription for the current partner was considered as an option, more commonly for the low risk than the high risk case (45\% vs 24\%). Notification and treatment of ex-partners or casual partners was largely left to the responsibility of the patient. In additional comments GPs made clear that PN/PT steps depend on patient- and partner profiles and the character of their relationship (e.g. steady, longterm or casual) as well as the connection between GP and patient.

Most of the GPs agreed PIPT can be a means to reduce re-infections from chlamydia (62\%). GPs said to be open to the idea of PIPT: a considerable

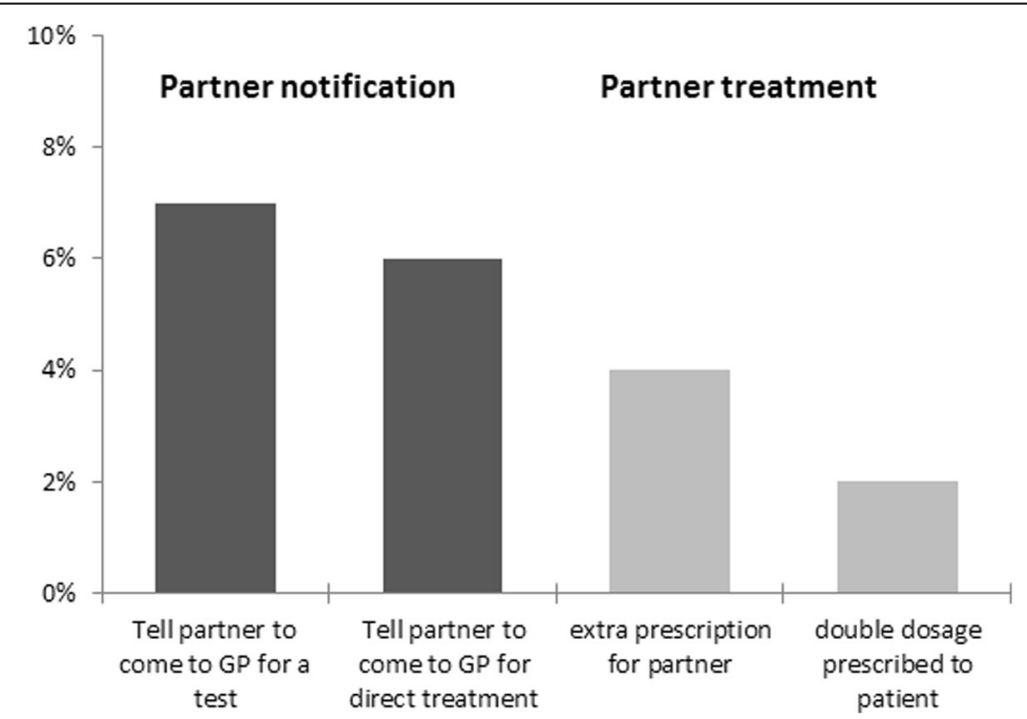

Fig. 2 Proportion of 94 chlamydia-positive cases seen by GP for whom one of the specified partner treatments was applied (Sentinel Practices, NIVEL PCD 2015) 


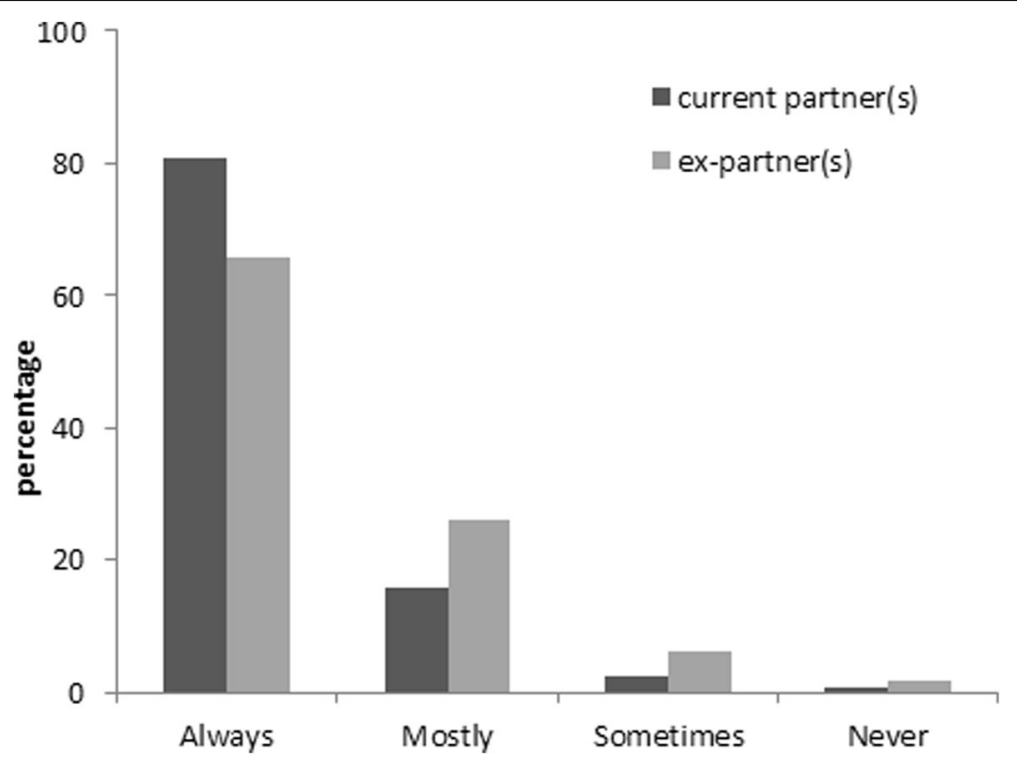

Fig. 3 Proportion of 1411 GPs (answering pre-conference questionnaire, Nov 2015) indicating to discuss partner notification with patients diagnosed with an STI, for current partner(s) and for ex-partners

proportion of GPs indicated it should be an option for some patients $(36 \%)$, for most patients $(21 \%)$ or all (10\%). Important advantages were mentioned, especially better infection control and better chances to treat the partner, also practical ones in the sense that it would make PT easier and cheaper. On the other hand, a range of disadvantages were also mentioned. The main objections seem to lie in the uncertainty whether the medication will reach the right person and that there is no chance to give advice to the partner or check his/her risk for allergies or contra-indications. Furthermore over-treatment, potentially leading to resistance, issues on patient privacy, and the fact that the partner may have other STIs or have contact with other partners were mentioned.

\section{Discussion}

\section{Findings}

This first study about PN and PT of chlamydia in the general practice in the Netherlands shows that GPs currently perform an advisory rather than active, facilitating

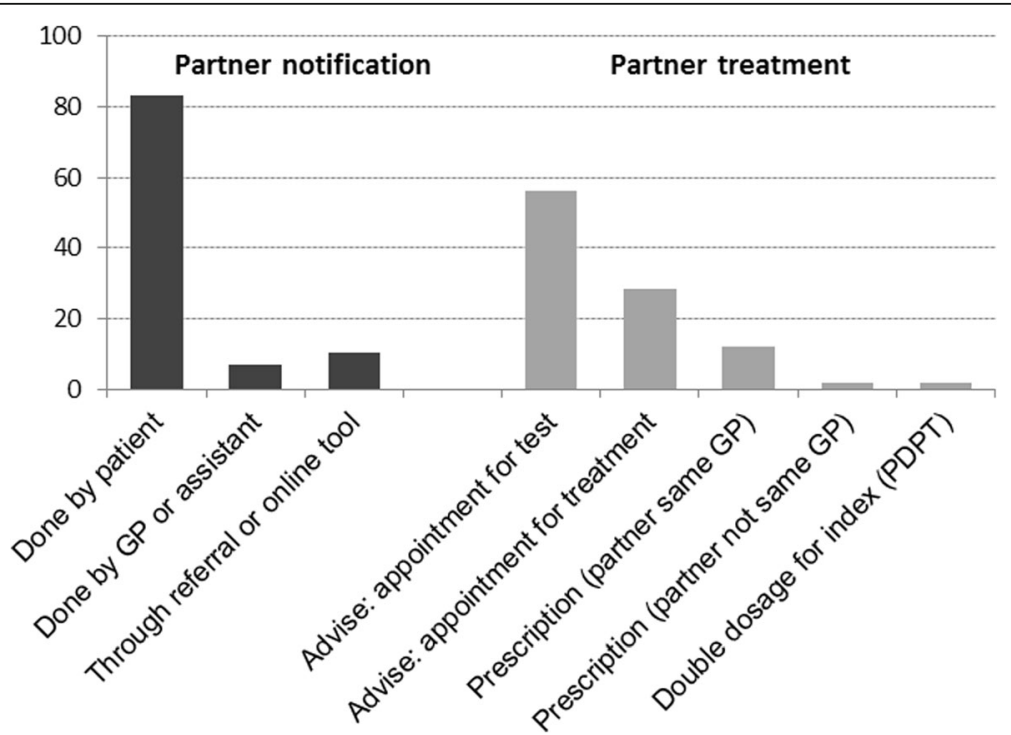

Fig. 4 Proportion of 271 GPs (answering 'multiple choice' questions at conference, Nov 2015) reporting on most common method used for partner notification and partner treatment for patients diagnosed with chlamydia 
Table 2 Partner notification and partner treatment practices indicated by 289 GPs for the two 'vignettes' of chlamydia cases presented in the questionnaire (NIVEL PCD 2016)

\begin{tabular}{|c|c|c|c|}
\hline & $\begin{array}{l}\text { Case 1: } \\
\text { low risk }\end{array}$ & $\begin{array}{l}\text { Case 2: } \\
\text { higher risk }\end{array}$ & Total \\
\hline \multicolumn{4}{|l|}{ Partner notification $(\mathrm{PN})^{\mathrm{a}}$} \\
\hline Discuss with patient, let patient do PN him/herself & $93 \%{ }^{\mathrm{b}}$ & $81 \%^{\mathrm{b}}$ & $87 \%$ \\
\hline Discuss and offer to do PN by GP or assistant & $22 \%$ & $26 \%$ & $24 \%$ \\
\hline Refer to MHS or use PN website & $37 \%{ }^{b}$ & $74 \%^{\mathrm{b}}$ & $55 \%$ \\
\hline \multicolumn{4}{|l|}{ Partner treatment (PT)a } \\
\hline Advise to get the partner to consult the GP for a test & $72 \%^{\mathrm{b}}$ & $81 \%^{\mathrm{b}}$ & $76 \%$ \\
\hline Advise to get the partner to consult a GP for direct treatment & $52 \%$ & $59 \%$ & $55 \%$ \\
\hline Prescribe antibiotics for the partner & $18 \%$ & $14 \%$ & $16 \%$ \\
\hline Prescribe a double dosage to patient to treat his/her partner & $5.6 \%$ & $6.9 \%$ & $6.3 \%$ \\
\hline Prescribe $A B$ to partner after patient has done PN & $45 \%^{\mathrm{b}}$ & $24 \%^{\mathrm{b}}$ & $34 \%$ \\
\hline
\end{tabular}

amultiple choice questions, more than 1 answer possible

${ }^{b}$ significant difference between low risk and high risk, at $p<0.05$. PN = partner notification; PT = Partner Treatment

role in chlamydia $\mathrm{PN}$ and $\mathrm{PT}$. In some cases they provide actual PIPT. In general, GPs discuss PN of current and ex-partners with chlamydia patients but leave it to the patient to carry it out. PIPT is applied in an estimated $2-6 \%$ of chlamydia cases, based on questionnaires and available electronic consultation- and prescriptiondata. We found that when the partner is also registered as a patient in the same practice, GPs are more inclined to implement PIPT, i.e. in $12-21 \%$ of chlamydia cases. PIPT for unseen/unknown partners is not yet in line with legal regulations.

Follow-up of partner notification and treatment in general practice needs more attention. GPs appeared to be open to the idea of PIPT, although they also expressed concerns, disadvantages and risks. PIPT was an option for about one in five GPs. PN/PT intentions may depend on the STI-risk behaviour of the patient: a high-risk case (with multiple recent partners) would be referred to (online) PN services more often than a low risk case, while a low-risk case with a steady relationship and a partner registered in the same practice was more likely to receive PIPT, especially if the patient would have notified the partner first. PN/PT steps also depend on the connection between GP and patient.

\section{Strengths and limitations}

The strength of our study was the use of multiple datasources (questionnaires, consultation- and pharmacy data) and the access to representative groups of GPs for questionnaire surveys (via the large national GP conference and the NIVEL-PCD network). We have combined data on intentions and opinions with estimates of PN/PT from GP registers and thereby obtained much better insight into practice and attitude towards PN and PIPT.

Some sources provided more in-depth information than others. The questionnaires used for the (pre)conference surveys were short and with the instruction to choose one 'most applicable' answer (multiple choice), more subtle nuances may have been lost. The vignette study on the other hand offered more room for opinions and thoughts, giving insight in opportunities and challenges foreseen for PIPT implementation. Intentions to use PIPT seemed higher than actual practice, maybe due to the discrepancy between intention and implementation but might also indicate that GPs would like to apply PIPT more often but are restricted by guidelines or regulations. Risk profiles of patients (e.g. sexual preference) are not described in regular patient records, so the actual insight into $\mathrm{PN} / \mathrm{PT}$ practice of GP's in high risk groups was limited.

The information on PIPT from prescription data had major limitations. The national pharmacy data showed a small but increasing proportion of Azithromycin prescribed as double dosage, but without the indication for the medication, we cannot be certain these were for chlamydia. Moreover, the recent update of the GP STI guideline (end of 2013), [7] provides a 3rd choice treatment option of Azithromycin $2 \mathrm{~g}$ single dose for gonorrhoea, for patients for whom Ceftriaxone is contraindicated and the resistance pattern unavailable. We saw a clear rise in double dosages from 2013 onwards as well as an unequal gender distribution of the double dosages, which suggests these prescriptions may be for gonorrhoea rather than for chlamydia, because gonorrhoea is seen more commonly in men than in women [1], due to the sexual network (MSM) and symptomatic nature of infections in men, urging them to visit their GP. Probably, the level before 2013 (0.4-0.5\%) shows the actual proportion of double dosages for patient and partner prescription. In the NIVEL-PCD, part of the double/repeated prescriptions of antibiotics seems unlikely to be PIPT. Double dosages of Doxycycline were prescribed in more than $30 \%$ of cases, especially in men (46\%); we 
suspect these relate to other diagnoses including (acute) epididymitis or PID, for which a prolonged course is indicated. The repeated prescriptions on 1 day may also have been registration artefacts, due to back reporting from pharmacies after patients receive the medication. Hence, to be able to use prescription data to monitor PIPT, more reliable information on the prescription and its indication is required. The registration in the national pharmacy database would be improved by including the indication of prescriptions. Prescription data from the GP electronic patient registration would be improved by adapting software to extract more exact dosage schemes and clarifying whether or not back-reporting from the pharmacy takes place in the one or more of the current registration software systems in use.

\section{Comparison to other studies and countries}

We found that the implementation of PIPT for chlamydia is currently low among GPs in the Netherlands, while GPs showed a higher intention to use PIPT when presented with hypothetical chlamydia cases and after PIPT principles were explained briefly. The low level is not surprising, as in the current legal system in the Netherlands the GP should have contact with the partner, before prescribing antibiotics, to check medical history and allergies and inform about the reason for prescription. [25] In fact, some of the cases of PIPT in the records may have been given without observing the law. In other countries where PIPT is legal, levels of uptake are still relatively low: in the US, in a national survey of more than 3000 physicians who treat patients for STIs, approximately $50 \%$ reported ever using PIPT, while only $11 \%-14 \%$ of physicians reported usually or always using PIPT. [26] In New York City, the number of expedited partner therapy prescriptions was found to be low and vary greatly between pharmacies in New York City. [27] In the UK, in a pilot RCT the proportion of partners treated after partner details (medical history and allergies) were communicated via the phone $(35 \%)$ or at pharmacy $(46 \%)$ did not exceed that by standard patient referral (45\%). [18]

In our vignette study, GPs have shown to be aware of the beneficial effects of PIPT in preventing further transmission and facilitating partner management procedures for chlamydia, as has been assessed in effectiveness studies in other countries (US [13-16], UK [28]) and reviews reporting an overall $20-29 \%$ reduction of reinfection. [6, $29,30]$ Besides the effect on transmission, PIPT can simplify procedures for the partner, which will make treatment much faster. The few cases that may receive PIPT, according to the present study, appear to be at relatively low risk, with a steady partner who is patient in the same practice. Successful treatment of current partners is most important for preventing reinfection of index cases and reducing further transmission of chlamydia at the population level. On the other hand, also for casual partners, or when it is likely that partners will not seek treatment and are at high risk of infection, PIPT is a good last option or 'better than nothing' [31]. Modelling studies by Althaus [32,33] showed that PN for partners up to 18 months back would identify $10 \%$ infections in notified partners.

The GPs in our study also mentioned important barriers to implement PIPT, which have been reported in the literature as well. [30, 31] GPs stated in the questionnaire that PIPT reduces the opportunity for the partner to see a professional and get further STI counselling and advice. [34] Current legislation requires direct contact with partners. It remains unclear if contact by telephone is sufficient to meet the legal requirements for the prescription of a drug. It is defendable that under certain conditions contact by telephone with a partner will suffice, but the applicable law nor the existing case law gives a decisive answer to that question. Contacting partners via internet would however certainly require a change in legal requirements. Current GP guidelines on partner notification should be extended with a specification of how and when PIPT can be applied (for partners in the same practice and/or when timely treatment is impossible without PIPT). A further concern is that the patient may not reach his/her partner(s) so partner uptake is not guaranteed. $[19,35]$ The partner may have other STIs or have sexual contact with other partners, which would not be traced with PIPT. [36] Potential over-treatment by PIPT is a real concern, as only $35 \%$ of those notified for chlamydia are found infected. [1] Following antibiotic stewardship, careful use of antibiotics is advocated and embedded in the Dutch habit of relatively low use of antibiotics in patient care in general (the lowest in Europe [37]). Resistance of chlamydia to Azithromycin is not an urgent threat, [38] but for gonorrhoea, a common co-infection with chlamydia which could go unnoticed with PIPT, it is on the rise. [39] Furthermore, in case of an anal (co)infection, chlamydia should be treated with Doxycycline and not just Azithromycin. $[7,8]$

\section{Conclusions/recommendations}

GPs in the Netherlands are open to implement PIPT for some chlamydia cases but not for all, provided there are clear guidelines, including clarity about legal options, and indications how PIPT can be applied and which patients and partners would be eligible for PIPT. We advise recommendations for partner treatment in GP guidelines to be extended with a specification of when and how PIPT can be applied.

\section{Endnotes}

${ }^{1}$ See: https://www.sfk.nl/english (accessed may 2017) 


\section{${ }^{2}$ See: $\quad$ www.nivel.nl/NZR/zorgregistraties-eerstelijn (accessed may 2017)}

\section{Abbreviations}

APT: Accelerated Partner Therapy; ATC: Anatomical Therapeutic Chemical classification system; EPT: Expedited Partner Therapy; GP: General Practitioner; ICPC: International Coding Primary Care; MHS : Municipal Health Services; PIPT: Patient Initiated Partner Therapy; PN: Partner Notification; PT: Partner Treatment; STI: Sexually Transmitted Infection

\section{Acknowledgements}

We want to acknowledge all GPs for their participation in questionnaires. We are grateful to the GPs in the NIVEL-PCD network for their cooperation in supplying anonymised patient data and especially the GPs of the sentinel practices (Peilstations) for the extra questionnaires on STI consultations. Furthermore, the authors appreciate the input from the other PICCUP project members: $F$ van Aar, G Haringhuizen (RIVM), A Watzeels, A Nanhoe (GGD Rotterdam Rijnmond), C Phillips-Santman (Leiden UMC) and G Kok (Maastricht University).

\section{Funding}

The project received funding from ZonMW (The Netherlands Organisation for Health Research and Development), research grant number 5220020.

\section{Availability of data and materials}

Data are available on request via correspondent or last author.

\section{Authors' contributions}

IvdB coordinated the data collection and analyses of the various datasources and wrote the draft versions of the manuscript. GD was involved in the parts of study on NIVEL-PCD (questionnaire and data), KH analysed the prescription data from NIVEL-PCD and drafted the related part of the manuscript. All authors, including JEvB, BHvB and HMG, were involved in the overall design of the study, follow-up of progress and commenting on earlier versions of the manuscript. All authors read and approved the final manuscript.

\section{Ethics approval and consent to participate}

For patient-derived data from the NIVEL-PCD and the national pharmacy data (SFK), ethics approval via an METC was not needed, as explained in the 'Privacy statement NIVEL PCD': Dutch law allows the use of electronic health records for research purposes under certain conditions. According to this legislation, neither obtaining informed consent from patients nor approval of a medical ethics committee is obligatory for this type of observational studies containing no directly identifiable data (Dutch Civil Law, Article 7:458; http:// www.dutchcivillaw.com/civilcodebook077.htm). This study has been approved by the applicable governance bodies of NIVEL Primary Care Database under nr. NZR00316.012).

For the national pharmacy database, SFK, privacy regulations guarantee the privacy of the participating pharmacists. With regard to the prescribing doctor and the patient, the SFK only uses anonymously gathered data. Respondent GPs (questionnaires) gave informed consent for use of anonymised data for publication.

\section{Consent for publication}

Not applicable.

\section{Competing interests}

The authors declare that they have no competing interests.

\section{Publisher's Note}

Springer Nature remains neutral with regard to jurisdictional claims in published maps and institutional affiliations.

\section{Author details}

'Epidemiology and Surveillance Unit, Centre for Infectious Diseases Control, RIVM, Bilthoven, The Netherlands. ${ }^{2}$ NIVEL Primary Care Database, Sentinel Practices, Utrecht, The Netherlands. ${ }^{3}$ NIVEL Primary Care database, Utrecht, The Netherlands. ${ }^{4}$ Epidemiology and Surveillance Unit, Centre for Infectious Diseases Control, RIVM, Bilthoven, The Netherlands. ${ }^{5}$ Department of General Practice, Academic Medical Center, Amsterdam; STI AIDS Netherlands,
Amsterdam, The Netherlands. ${ }^{6}$ Department of Infectious Disease Control, Municipal Public Health Service Rotterdam-Rijnmond, Rotterdam, The Netherlands. 'Department of Public Health, Erasmus MC—University Medical Center Rotterdam, Rotterdam, The Netherlands.

Received: 17 July 2017 Accepted: 30 November 2017

Published online: 20 December 2017

\section{References}

1. van den Broek I, van Aar F, van Oeffelen A, et al.: Sexually transmitted infections in the Netherlands in 2015. In: RIVM report. vol. 2016-0027. Bilthoven, The Netherlands: RIVM; 2016.

2. Götz H, Wolfers M, Luijendijk A, van den Broek I. Retesting for genital Chlamydia trachomatis among visitors of a sexually transmitted infections clinic: randomized intervention trial of home- versus clinic-based recall. BMC Infect Dis. 2013;13:239.

3. Hosenfeld C, Workowski K, Bouman S, Zaidi A, Dyson J, Mosure D, Bolan G, Bauer $\mathrm{H}$. Repeat infection with Chlamydia and gonorrhea among females: a systematic review of the literature. Sex Transm Dis. 2009;36(8):478-89.

4. Kampman C, Koedijk F, Driessen-Hulshof H, Hautvast J, van den Broek I. Retesting young STI clinic visitors with urogenital Chlamydia trachomatis infection in the Netherlands; response to a text message reminder and reinfection rates: a prospective study with historical controls. Sex Transm Infect. 2016:92(2):124-9.

5. Geisler W, Lensing S, Press C, Hook E. Spontaneous resolution of genital Chlamydia trachomatis infection in women and protection from reinfection. J Infect Dis. 2013;207(12):1850-6.

6. Ferreira A, Young T, Mathews C, Zunza M, Low N. Strategies for partner notification for sexually transmitted infections, including HIV. Cochrane Database Syst Rev. 2013;3(10):CD002843.

7. Van Bergen J, Dekker J, Boeke A, Kronenberg E, Van der Spruit R, Burgers J, Bouma M, Verlee E. Dutch GP guideline on STI consultations [guidelines in Dutch: NHG-Standaard het soa-consult (Eerste herziening)]. Huisarts en Wetenschap. 2013;56:450-63.

8. de Vries H, van Doornum G, Bax C, al. e: Multidisciplinary guidelines sexually transmitted diseases secondary care [guidelines in Dutch: Multidisciplinaire Richtlijn Seksueel Overdraagbare Aandoeningen voor de 2e Lijn]. In. Nederlandse Vereniging voor Dermatologie en Venereologie; 2012. www.huidarts.info.

9. Gotz HM, van Rooijen MS, Vriens P, Op de Coul E, Hamers M, Heijman T, van den Heuvel F, Koekenbier R, van Leeuwen AP, Voeten HA. Initial evaluation of use of an online partner notification tool for STI, called 'suggest a test': a cross sectional pilot study. Sex Transm Infect. 2014;90(3):195-200.

10. Voeten HACM: Anoniem sekspartners waarschuwen? Het kan via www. partnerwaarschuwing.nl. Medisch Farmaceutische Mededelingen, praktijkgerichte nascholing over farmacotherapie, 27 oktober 2016 (https:// www.pil-nascholing.nl/tijdschrift/editie/artikel/t/anoniem-sekspartnerswaarschuwen).

11. Centers for Disease Control and Prevention: Expedited partner therapy in the management of sexually transmitted diseases.. In. Edited by US DEpartment of Health and Human Services. Atlanta, GA; 2006.

12. Oliver A, Rogers M, Schillinger J: The Impact of Prescriptions on Sex Partner Treatment Using Expedited Partner Therapy for Chlamydia trachomatis Infection, New York City, 2014-2015. Sex Transm Dis. 2016;43(11):673-78.

13. Schillinger J, Kissinger $P$, Calvet $H$, Whittington W, Ransom $R$, Sternberg $M$, Berman S, Kent C, Martin D, Oh M, et al. Patient-delivered partner treatment with azithromycin to prevent repeated Chlamydia trachomatis infection among women: a randomized, controlled trial. Sex Transm Dis. 2003;30(1):49-56.

14. Golden M, Whittington W, Handsfield H, Hughes J, Stamm W, Hogben M, Clark A, Malinski C, Helmers J, Thomas K, et al. Effect of expedited treatment of sex partners on recurrent or persistent gonorrhea or chlamydial infection. N Engl J Med. 2005;352(7):676-85.

15. Kissinger $P$, Mohammed $H$, Richardson-Alston G, Leichliter J, Taylo S, Martin $D$, Farley T: Patient-delivered partner treatment for male urethritis: a randomized, controlled trial. Clin Infect Dis 2005, 41(5):623-629.

16. Golden M, Kerani R, Stenger M, Hughes J, Aubin M, Malinski C, Holmes K. Uptake and population-level impact of expedited partner therapy (EPT) on Chlamydia trachomatis and Neisseria gonorrhoeae: the Washington state community-level randomized trial of EPT. PLoS Med. 2015;12(1):e1001777.

17. Legal Status of EPT - Summary Totals (July 1, 2016). See: website Centers for Disease Control and Prevention, section Sexually Transmitted Diseases: https://www.cdc.gov/std/ept/legal/totals.htm. 
18. Estcourt C, Sutcliffe L, Copas A, Mercer C, Roberts T, Jackson L, Symonds M, Tickle L, Muniina P, Rait G, et al. Developing and testing accelerated partner therapy for partner notification for people with genital Chlamydia trachomatis diagnosed in primary care: a pilot randomised controlled trial. Sex Transm Infect. 2015;91(8):548-54.

19. Cameron S, Glasier A, Muir A, Scott G, Johnstone A, Quarrell H, Oroz C, McIntyre M, Miranda D, Todd G. Expedited partner therapy for Chlamydia trachomatis at the community pharmacy. BJOG. 2010;117(9): 1074-9.

20. Dombrowski J, Golden M. Accelerated partner therapy: a promising new partner treatment option. Sex Transm Infect. 2012;88(1):2-3.

21. Van den Broek IV, Donker GA, Hek K, Van Benthem BHB, van Bergen JEAM, Götz HM P3.224 Partner notification and partner treatment for chlamydia: atttitude and practice of general practitioners in the Netherlands. Sexually Transmitted Infections. 2017;93(Suppl 2):A177. doi:10.1136/sextrans-2017053264.459 .

22. van den Broek I, Verheij R, van Dijk C, Koedijk F, van der Sande M, van Bergen J. Trends in sexually transmitted infections in the Netherlands, combining surveillance data from general practices and sexually transmitted infection centres. BMC Fam Pract. 2010;11:39.

23. Peabod J, Luck J. P G, Jain S, Hansen J, spell M: measuring the quality of physician practice by using clinical vignettes: a prospective validation study. Ann Intern Med. 2004;141(10):771-80.

24. Peabody J, Luck J, Glassman P, Dresselhaus T, Lee M. Comparison of vignettes, standardized patients, and chart abstraction: a prospective validation study of 3 methods for measuring quality. JAMA. 2000; 283(13):1715-22.

25. Geneesmiddelenwet. Hoofdstuk 6: Terhandstelling van geneesmiddelen en het voorschrijven daarvan (Artikelen 61-68), See: http://wetten.overheid.nl/ BWBR0021505/2016-08-01\#Hoofdstuk6 (accessed May 2017).

26. Hogben M, McCree DH, Golden MR. Patient-delivered partner therapy for sexually transmitted diseases as practiced by U.S. physicians. Sex Transm Dis. 2005;32(2):101-5.

27. Okah E, Arya V, Rogers M, Kim M, Schillinger JA. Sentinel surveillance for expedited partner therapy prescriptions using pharmacy data, in 2 new York City neighborhoods, 2015. Sex Transm Dis. 2017:44(2):104-8.

28. Cameron S, Glasier A, Scott G, Young H, Melvin L, Johnstone A, Elton $R$. Novel interventions to reduce re-infection in women with chlamydia: a randomized controlled trial. Hum Reprod. 2009;24(4): 888-95.

29. Hogben M, Collins D, Hoots B, O'Connor K: Partner Services in Sexually Transmitted Disease Prevention Programs: a review. Sex Transm Dis 2016, 43(2 Suppl 1):S53-S62.

30. Gannon-Loew K, Holland-Hall C, Bonny A: A Review of Expedited Partner Therapy for the Management of Sexually Transmitted Infections in Adolescents. J Pediatr Adolesc Gynecol 2017, Feb 3. pii: S10833188(16)30276-5. doi: https://doi.org/10.1016/j.jpag.2017.01.012. [Epub ahead of print].

31. Pavlin N, Parker R, Piggin A, Hopkins C, Temple-Smith M, Fairley C, Tomnay J, Bowden F, Russell D, Hocking J, et al. Better than nothing? Patientdelivered partner therapy and partner notification for chlamydia: the views of Australian general practitioners. BMC Infect Dis. 2010;10:274. https://doi. org/10.1186/1471-2334-1110-1274.

32. Althaus C, Turner K, Mercer C, Auguste P, Roberts T, Bell G, Herzog S, Cassell J, Edmunds W, White $P$, et al. Effectiveness and costeffectiveness of traditional and new partner notification technologies for curable sexually transmitted infections: observational study, systematic reviews and mathematical modelling. Health Technol Assess. 2014;18(3):1-100.

33. Althaus CL, Heijne JC, Herzog SA, Roellin A, Low N. Individual and population level effects of partner notification for Chlamydia trachomatis. PLoS One. 2012;7(12):e51438.

34. Rosenfeld E, Marx J, Terry M, Stall R, Flatt J, Borrero S, Miller E. Perspectives on expedited partner therapy for chlamydia: a survey of health care providers. Int J STD AIDS. 2016;27(13):1180-6.

35. Goldsworthy R, Fortenberry D. Patterns and determinants of patientdelivered therapy uptake among healthcare consumers. Sex Transm Dis. 2009;36(1):25-32.

36. Forbes $\mathrm{G}$, Clutterbuck D. How many cases of chlamydial infection would we miss by not testing partners for infection? Int J STD AIDS. 2009;20(4):267-8.
37. OECD Health Statistics: Health at a Glance: Europe 2016: State of Health in the EU Cycle. Overall volume of antibiotics prescribed, 2014 (or nearest year). In. DOl:https://doi.org/10.1787/health_glance_eur-2016-graph115-en: OECD; 2016.

38. Kong F, Hocking J: Treatment challenges for urogenital and anorectal Chlamydia trachomatis. BMC Infect Dis 2015, 15(293):doi: https://doi.org/10. 1186/s12879-12015-11030-12879.

39. Wind CM, van der Loeff MF S, van Dam AP, de Vries HJ, van der Helm JJ. Trends in antimicrobial susceptibility for azithromycin and ceftriaxone in Neisseria gonorrhoeae isolates in Amsterdam, the Netherlands, between 2012 and 2015. Euro surveillance. 2017:22:1.

\section{Submit your next manuscript to BioMed Central and we will help you at every step:}

- We accept pre-submission inquiries

- Our selector tool helps you to find the most relevant journal

- We provide round the clock customer support

- Convenient online submission

- Thorough peer review

- Inclusion in PubMed and all major indexing services

- Maximum visibility for your research

Submit your manuscript at www.biomedcentral.com/submit
) Biomed Central 